\title{
Oracle: The Articulation of Promise
}

\author{
Amy Cunningham \\ University of Brighton \\ Faculty of Arts, University of Brighton, Grand Parade, Brighton, East Sussex BN2 0JY, UK \\ a.cunningham@brighton.ac.uk
}

\section{INTRODUCTION}

Oracle: The Articulation of Promise is an artwork created by Amy Cunningham for sung voice and single screen video. Taking the form of a video installation and a live performance it was first exhibited with the title Oracle as part of Autumn Almanac: The Voice and the Lens at IKON Gallery Birmingham in November 2012, curated by Sam Belinfante and Third Ear (IKON Gallery 2012).

\section{OBSOLETE PIONEERING TECHNOLOGY AND THE CRITICAL ROLE OF THE FEMALE VOICE}

Oracle was conceived as a video song cycle in response to the phenomenon of nostalgia for pioneering yet obsolete technologies. It was also intended to explore the role of the singing voice as a critical tool in video art. In this work pre-existing material was re-imagined, after which the resulting footage was then combined together with original vocal music, using reflection, layering and montage. Key materials used were writings by the 19th century mathematician and analyst Ada Lovelace who interpreted the Analytical Engine, the first fully automatic and universal computer, invented by Charles Babbage in 1834 (Krysa 2011). It was intended that the 'off-screen' disembodied singing voices in Oracle would echo the critical and analytical role that Lovelace took in her work, as exemplified in her letters to Babbage and in her translation notes, from which extracts were used as lyrics and text in the video work.

\subsection{Process and Context}

The title, 'Articulation of Promise' is borrowed from a description of Lovelace's ability to analyse, communicate and imagine the future: 'She understood the plans for the device as well as Babbage but was better at articulating its promise.' (Maisel and Smart 1997). The term 'Oracle' draws upon two references. One is a reference to the Delphic Oracle in Greek mythology, associated with the female 'pythia' (Connor 2000), who perhaps like Lovelace in her communication role between theory and practical use, took the position of mediator between the spirits and the prophets. The second is the name of the first 'Teletext' service used by the Independent Broadcasting Association in the U.K. Teletext which, could be considered a forerunner of the Internet and loom-like wove patterns within the spare scan lines of the television image, finished broadcasting in 2012 and has now itself become part of the narrative of the obsolete. Lovelace thought creatively about the Analytical Engine, and compared its algebraic patterns to the Jacquard Loom. She also predicted that the computer could be used to generate music, poetry and images. (Krysa 2011).

The combination of rational logic and the poetic was important in the creation of Oracle, in which the singing voice can slide disarmingly between the subjective and the objective, and the video image has the ability to contain divergent, fictional and factual references.

\section{REFERENCES}

Connor, S. (2000) Dumbstruck: The Cultural History of Ventriloquism. Oxford University Press, Oxford.

IKON Gallery (2012) Programme: Past: Autumn Almanac: The Voice and the Lens, http://www.ikongallery.co.uk/programme/past/event 1713/autumn_almanac_the_voice_and_the_lens/ (29th March 2013)

Krysa, J. (2011) Ada Lovelace, (doCUMENTA (13): 100 Notes - 100 Thoughts, no. 055). Hatje Cantz Verlag, Ostfildern.

Maisel, M. and Smart, L. (1997) Ada Lovelace: Founder of Scientific Computing, http://www.sdsc.edu/ScienceWomen/lovelace.html (29th March 2013) 


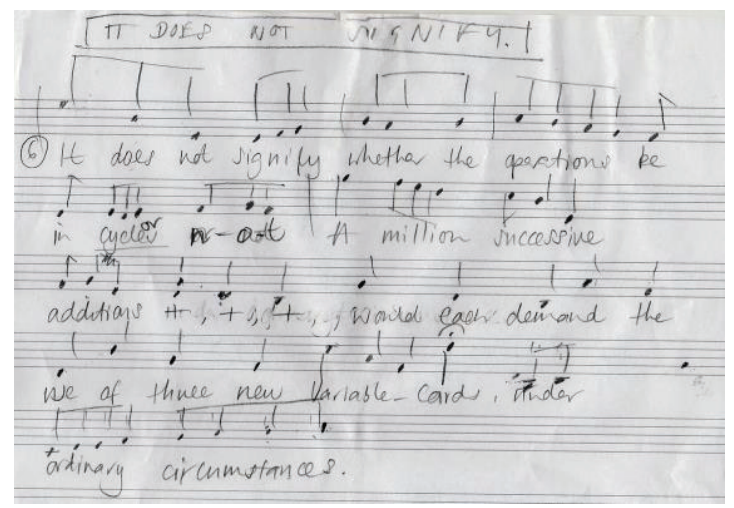

Figure 1: Extract of score for Oracle, by Amy Cunningham, 2012

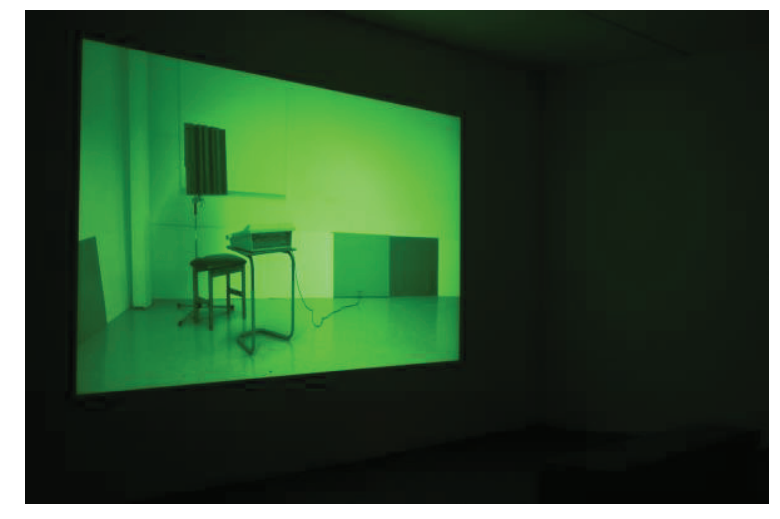

Figure 2: Still from installation view of Oracle, by Amy Cunningham, IKON Gallery, 2012

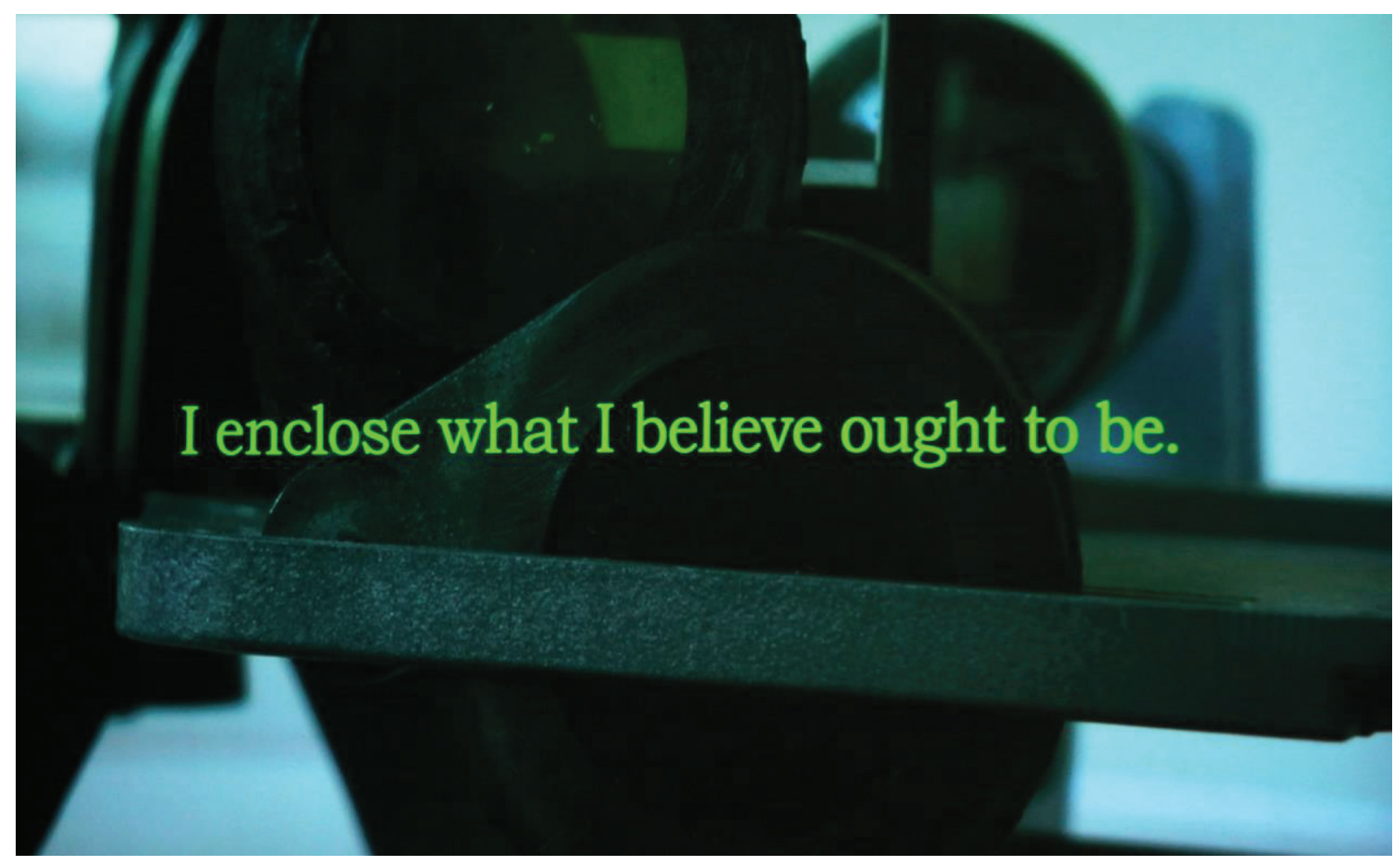

Figure 3: Still from Oracle, by Amy Cunningham, IKON Gallery, 2012 